\title{
NACIONAL FINANCIERA DURANTE LA INDUSTRIALIZACIÓN VÍA SUSTITUCIÓN DE IMPORTACIONES EN MÉXICO
}

\section{NACIONAL FINANCIERA DURING THE MEXICAN INDUSTRIALIZATION VIA IMPORT SUBSTITUTION}

\author{
Pablo J. López* \\ Universidad de Buenos Aires, Buenos Aires, Argentina, <pablojlopez@hotmail.com>
}

Resumen. El propósito de este trabajo es repasar la historia de Nacional Financiera S. A. como banco de fomento en relación con el sector industrial, entre 1940 y 1982 , con el objetivo de comprender sus principales características y sus limitaciones más importantes respecto al proceso de industrialización vía sustitución de importaciones. Para cumplir este objetivo resulta necesario enmarcar la participación de la institución en la lógica del proceso de industrialización y las políticas económicas mexicanas. Por las propias características del objeto de estudio y de la metodología de análisis, es necesario incluir este trabajo entre los debates acerca de los problemas de la sustitución de importaciones en América Latina y, en particular, las discusiones sobre la industrialización mexicana.

Palabras clave: bancos de desarrollo, industrialización, capitales extranjeros.

Abstract. In Mexico, although Nacional Financiera S. A. was founded in the midthirties, it was defined as a development bank in the early forties, with the beginning of the import substitution industrialization process. Therefore, the purpose of this study is to revise the history of the institution and its relation with the industrial sector between 1940 and 1982. In order to do so, we believe it is necessary to take into account the logic of the industrialization process and the Mexican economic policies. Thus, this work aims to be a contribution to the study of the role played by the financial structure in the industrialization process in Mexico. Also, due to the characteristics of the subject of this study and the methodology, this work fits in the discussion about the problems of the import substitution industrialization in Latin America, and in particular the debates on the Mexican industrialization.

Key words: development banks, industrialization, import substitution, foreign capital.

Fecha de recepción: enero de 2011. Fecha de aceptación: agosto de 2011.

* Agradezco a los dictaminadores anónimos de este artículo, cuyas valiosas sugerencias se recogen en gran medida en esta versión y que indudablemente contribuyeron a mejorar el trabajo. Por supuesto, quedan eximidos de cualquier responsabilidad respecto del resultado final.

Am. Lat. Hist. Econ., año 19, núm. 3, septiembre-diciembre, 2012, pp. 129-163 


\section{INTRODUCCIÓN}

$\mathrm{N}$ acional Financiera S. A. (NAFINSA), creada en 1934 y consolidada como banco de fomento estatal a partir de 1940, se constituyó, en las décadas siguientes, en la segunda institución financiera en importancia del país, detrás del Banco de México. Este trabajo recorre la vida de la institución hasta 1982, periodo durante el que el Estado tuvo una participación importante en la movilización de recursos para favorecer el desarrollo de la industria a través de diversas políticas e instituciones. En 1982, con el estallido de la crisis de la deuda, se empieza a diluir la estrategia de industrialización vía sustitución de importaciones (ISI) en la región $\mathrm{y}$, en consecuencia, el papel de la banca de desarrollo.

En los países de menor desarrollo relativo, sin acumulación previa de capital por parte de los empresarios ligados a la industria, sin mercados accionarios desarrollados ni bancos privados en condiciones de ofrecer créditos a largo plazo, el financiamiento industrial intentó resolverse a partir de mercados de créditos con alta participación estatal, como observaron Gerschenkron ${ }^{1}$ y Zysman. ${ }^{2}$ Es en este esquema que enmarcamos el análisis de NAFINSA.

En las décadas de 1960 y 1979 se publicaron algunos trabajos que analizaron la actuación de NAFINSA en el desarrollo de México. Es el caso de Moore, ${ }^{3}$ Blair, ${ }^{4}$ Aubey, ${ }^{5}$ Falkowski ${ }^{6}$ y Villa. ${ }^{7}$ Estos trabajos brindan elementos importantes para estudiar la historia de la institución, pero por una cuestión cronológica carecen de una mirada integrada de todo el periodo de ISI. Pocos estudios se realizaron luego de la década de 1970, Ramí$\mathrm{rez}^{8} \mathrm{y}$, más recientemente, $\mathrm{Ares}^{9}$ son dos excepciones. En el marco de una creciente y prolífera literatura sobre la historia del crédito y la banca en México, esta escasez de trabajos que revisen esta experiencia llama la atención. ${ }^{10}$

A la luz del avance en el estudio de la historia de la estructura financiera mexicana registrado en los últimos años, los trabajos existentes sobre Nacional Financiera carecen de una mirada integrada de su desempeño en relación con la estrategia de industrialización y con las características

\footnotetext{
${ }^{1}$ Gerschenkron, "Atraso”, 1973.

2 Zysman, Goverments, 1983.

${ }^{3}$ Moore, Evolución, 1963.

${ }^{4}$ Blair, "Nacional", 1964.

${ }^{5}$ Aubey, Nacional, 1966.

${ }^{6}$ Falkowski, Nacional, 1972.

${ }^{7}$ Villa, Nacional, 1976.

${ }^{8}$ Ramírez, Development, 1986.

9 Ares, "Estado", 2007.

${ }^{10}$ Ángel y Marichal, "Poder", 2003.
} 
del sistema financiero. En este sentido, a partir de una revisión exhaustiva de la literatura existente, de los informes anuales de la institución y de los testimonios de sus directores generales, este trabajo intenta brindar nuevas luces acerca del desempeño de NAFINSA como parte de la estructura financiera mexicana y en tanto expresión e instrumento de las estrategias de industrialización impulsadas entre 1940 y 1982.

Para cumplir con ese objetivo, el trabajo se estructura de la siguiente manera. En primer lugar, se describen, sintéticamente, las condiciones que llevaron a la creación de Nacional Financiera en 1934. Luego se inicia el análisis de su actuación entre 1940 y 1982. Si bien Nacional Financiera mantuvo una política de decidido apoyo a la industria y al desarrollo del país durante toda la etapa, la modalidad de su actuación sufrió cambios importantes a lo largo del periodo, lo que permite dividir el análisis en tres subetapas. La primera abarca la segunda guerra mundial y la inmediata posguerra hasta 1954. La segunda se extiende a lo largo del llamado desarrollo estabilizador, entre 1954 y 1970. La última etapa se despliega hasta 1982. Como se verá, se trata de periodos caracterizados por ciertas regularidades que permiten dividir el análisis de esta forma. Por último, se plantea una mirada de largo plazo para realizar un balance del desempeño de la institución.

\section{LOS PRIMEROS AÑOS DE NACIONAL FINANCIERA}

La revolución mexicana implicó un quiebre en la historia económica, política y social del país. En esos años comenzó una etapa de transformaciones que, con altas dosis de violencia, dio paso a la conformación del Estado moderno interventor en México, con nuevas instituciones y políticas económicas. ${ }^{11}$ La revolución implicó, a su vez, la destrucción del sistema financiero, dando lugar, desde la década de 1920, a un proceso de conformación de nuevas instituciones de importancia en los siguientes decenios.

A principios de la década de 1930, como consecuencia de la revolución y de la gran depresión, las instituciones financieras quedaron en posesión de una enorme cantidad de activos inmuebles que estaban afectando la liquidez del sistema bancario. ${ }^{12}$ Se decidió, entonces, crear una institución preparada para llevar adelante la tarea de liquidación directa o el frac-

${ }^{11}$ Gracida y Fujigaki, "Economía”, 2005.

${ }^{12}$ La Ley General de Instituciones de Crédito de 1932 fijó un plazo de tres años para que las instituciones de crédito enajenaran, cobraran o ejecutaran los bienes, créditos o hipotecas que aceptaron o se adjudicaron en pago y que no podían conservar en su activo. Sin embargo, ese plazo sólo atrasaba la resolución del problema y dificultaba la reorganización del sistema bancario por parte del gobierno. 
cionamiento y colonización de los inmuebles. También se encargaría de planear y dirigir el fraccionamiento de las tierras que el gobierno federal y ciertos grupos oficiales (como las liquidaciones de la Comisión Monetaria y de la Caja de Préstamos para Obras de Irrigación y Fomento de la Agricultura) tuvieron que adjudicarse por diversos motivos. Para cumplir con esos objetivos, Nacional Financiera fue creada en $1934 .{ }^{13}$ Además de las operaciones con inmuebles, la nueva institución tenía por mandato actuar como agente financiero del gobierno, así como contribuir a la creación de un mercado interno para bonos públicos y promover el mercado de acciones y bonos privados. ${ }^{14}$

En cuanto al capital inicial, el gobierno federal aportó una gran parte en forma de bienes y sólo una pequeña parte en efectivo (oro, moneda nacional y dólares). A su vez, de las acciones que se pusieron a disposición del sector privado, sólo fue suscrita una parte minúscula. ${ }^{15}$

La Ley de Crédito Agrícola de 1935 le quitó el mandato de administrar los bienes inmuebles, que pasó al ámbito exclusivo del Banco Nacional de Crédito Agrícola. NAFINSA quedó dedicada a ser agente financiero del gobierno y a promover el mercado de capitales. En estas condiciones, durante sus primeros años su participación fue escasa y todas sus operaciones estuvieron dirigidas a estimular las inversiones en bonos federales, estatales o locales. Sin embargo, hacia finales de 1940 se modificaron sus estatutos a partir de las necesidades que la guerra generaba sobre la economía mexicana, convirtiéndose la institución en un banco de fomento, cuya actuación sería importante en las décadas siguientes.

${ }^{13}$ En 1933 se firmó un decreto por el que se autorizó a la Secretaría de Hacienda y Crédito Público a crear Nacional Financiera. Este decreto no se cumplió, pero su contenido fue recogido en el decreto del 30 de abril de 1934 que derogó el anterior y creó a Nacional Financiera como institución nacional de crédito. También se crearon en esos años otras instituciones financieras como el Banco Nacional Hipotecario y de Obras Públicas, en 1933; el Banco Nacional de Comercio Exterior, en 1937, y el Banco Nacional de Crédito Ejidal.

${ }^{14}$ Las funciones que el decreto de 1934 reservaba para la nueva institución eran amplios y ambiciosos. Sin embargo, en la práctica, "Nacional Financiera nació como una entidad administradora y liquidadora de bienes rústicos y de créditos inmobiliarios que se hallaban en los activos de diversas instituciones gubernamentales". Nacional, Nacional, 1985, p. 33.

${ }^{15}$ Nacional, Legislación, 1994. Posteriormente se realizaron ampliaciones del capital con nuevas suscripciones de acciones. Sin embargo, el porcentaje de acciones en manos privadas se mantuvo siempre en niveles muy bajos. 
NAFINSA y su actividad empresarial, 1940-1954

Si bien durante el sexenio cardenista la industria recibió un primer impulso, es a partir de 1940 que puede hablarse del inicio del proceso de industrialización a gran escala. ${ }^{16}$ En los inicios de esa década, en correspondencia con la importancia que adquirió la industria en la estrategia económica, Nacional Financiera sufrió una transformación significativa.

La ley orgánica sancionada en diciembre de 1940 sostenía que la función de administrar bienes raíces dedicados a la agricultura no era compatible con la de contribuir a encauzar inversiones de capital a la organización y ampliación de empresas. El nuevo contexto reclamaba que NAFINSA se dedicara a esas últimas funciones. ${ }^{17}$ Así, la nueva legislación estableció que Nacional Financiera debía, además de regular el mercado de valores y de créditos a largo plazo, promover la inversión de capital en la organización, transformación y fusión de empresas.

Durante la presidencia de Ávila Camacho, de 1940 a 1946, el contexto internacional signado por la segunda guerra mundial y el todavía muy incipiente desarrollo industrial, exigió una participación fuerte del Estado en la economía, en el desarrollo de grandes proyectos industriales y de infraestructura, en áreas que generaban cuellos de botella significativos para el despliegue de la estructura industrial. ${ }^{18}$ En ese contexto, el destino del financiamiento de NAFINSA estuvo dominado por el sector de infraestructura y por la industria básica (véase cuadro 1).

Respecto al área de infraestructura, entre 1940 y 1947 fueron las obras de irrigación, el desarrollo de caminos y puentes y otras obras públicas las que predominaron en el destino de los recursos de NAFINSA. Para el desarrollo industrial resultaba importante el avance de la producción agraria, sector capaz de generar divisas y abastecer de alimentos a los centros urbanos. Luego de la reforma agraria aplicada en el periodo cardenista, se necesitaban grandes obras en el sector para impulsar la producción, así como el desarrollo de infraestructura de comunicaciones para su comer-

${ }^{16}$ Durante el sexenio cardenista existió un impulso sobre la industria, aunque este sector no era todavía el eje de la política económica, ni el principal componente del PIB. Sin embargo, esa segunda mitad de la década de 1930 resultó fundamental para el desarrollo industrial posterior.

${ }^{17}$ Nacional, Legislación, 1994, pp. 63-78. Al respecto véase también el discurso del presidente de México, Ávila Camacho, al abrir las sesiones ordinarias del Congreso de 1941, donde sostiene que NAFINSA debía asumir la función de ser fuente de crédito para fomentar industrias. Ávila, Primer, 1941.

${ }^{18}$ Ávila, Primer, 1941. 
CUADRO 1. USO DE LOS FONDOS DE NAFINSA

(PORCENTAJE)

\begin{tabular}{lcc}
\hline Sectores & 1940-1947 & 1948-1954 \\
& & \\
Infraestructura & 50.9 & 48.7 \\
$\quad$ Energía eléctrica & 3.3 & 20.1 \\
Transporte & 2.9 & 16.7 \\
Irrigación, caminos, puentes y otras obras públicas & 44.7 & 11.9 \\
Industrias & 24.0 & 29.8 \\
Básicas & 14.9 & 12.6 \\
Otras de transformación & 9.2 & 17.2 \\
Otras actividades & 25.1 & 21.5 \\
\hline
\end{tabular}

Fuente: elaboración propia con base en Nacional, Economía, 1978.

cialización. Más tarde, entre 1948 y 1954, dentro del sector de infraestructura ganaron peso los rubros de energía eléctrica y transporte.

Las industrias básicas dominaron el financiamiento volcado al sector industrial entre 1940 y 1947. El apoyo a estas se realizó, principalmente, a través de la participación directa de la institución en la creación y administración de diversas empresas; forma de intervención que había sido impulsada por la ley orgánica de $1940 .^{19}$ Así, en los primeros años, dominó el financiamiento a través de la compra de valores. Esta modalidad implicaba que la institución se involucraba en la administración y el desarrollo técnico de las empresas.

En este sentido, diversos autores destacan la importancia de la actividad empresarial de la institución entre 1941 y $1947 .{ }^{20}$ Esta labor empresarial se producía en el marco general de un modelo en el que se establecía que el Estado debía concentrarse en proyectos que, ya sea por la magnitud de la inversión inicial o por la baja o diferida rentabilidad, eran dejados de lado por el sector privado (véase gráfica 1 ). ${ }^{21}$

Uno de los proyectos más importantes desarrollados en esos años fue el de Altos Hornos de México, en el que Nacional Financiera tuvo un papel crucial debido a la magnitud de la iniciativa y del capital que se requería. ${ }^{22}$ Motivado por la insuficiencia de la iniciativa privada y la es-

${ }^{19}$ Nacional, Legislación, 1994, p. 63.

${ }^{20}$ Véanse Blair, "Nacional”, 1964; Falkowski, Nacional, 1972, y Ramírez, Development, 1986.

${ }^{21}$ Maxfield, Governing, 1990, y Bennett y Sharpe, "State", 1982.

${ }^{22}$ La construcción de esta empresa se basó en la utilización de equipos usados y reconstruidos importados de Estados Unidos. Como en otros casos, el proyecto fue iniciado por el sector 


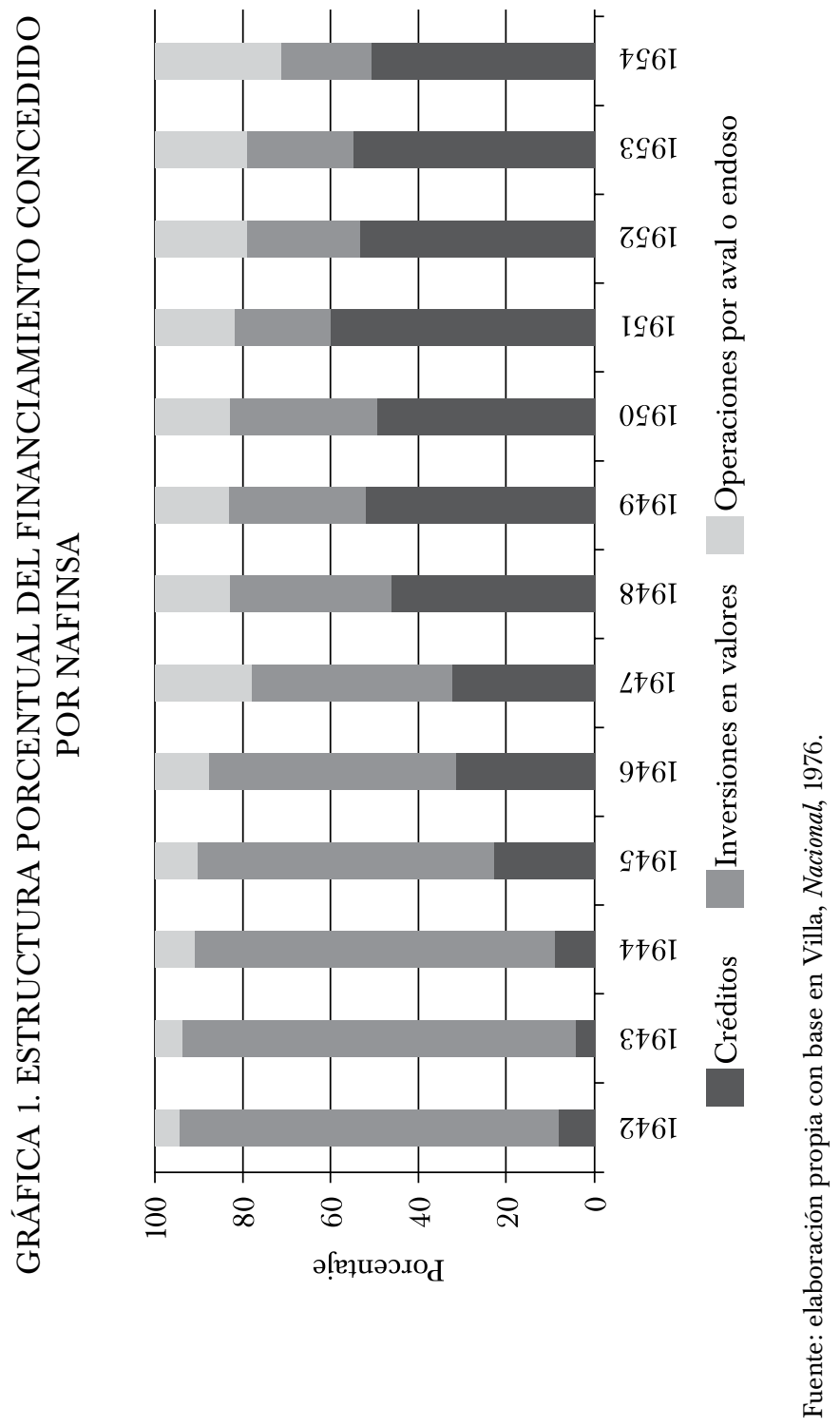


casez -producto de la segunda guerra mundial-, el Estado, a través de Nacional Financiera, realizó inversiones iniciales en otras industrias, consideradas clave para el desarrollo industrial, como el cemento y el papel. ${ }^{23}$ Así, se llenaban huecos en la industria mexicana y en el abastecimiento de importaciones.

Luego de la segunda guerra mundial, la importante labor de Nacional Financiera en la promoción industrial comenzó a diluirse y esto se expresó en una merma relativa de su participación como propietaria de firmas. $\mathrm{Si}$ bien en términos monetarios los recursos destinados a inversiones en valores se mantuvieron más o menos constantes, ante el crecimiento de los recursos de la institución se produjo una merma relativa de la adquisición de valores mientras fue cobrando mayor importancia el financiamiento a través de créditos (véase gráfica 1).

La menor actividad empresarial por parte de NAFINSA tuvo como punto de partida la reforma de su ley orgánica de 1947 que, además de ampliar el capital de la institución y facultarla para canalizar recursos del exterior, buscó limitar su actuación con el fin de que no invadiera las actividades de la banca privada. ${ }^{24}$

Según el decreto de 1947, la institución no debía abandonar su papel de promotor industrial, ${ }^{25}$ aunque las directrices para la cesión de recursos quedaban supeditadas a la actuación del sector privado, ya que NAFINSA debía, antes de otorgar financiamientos, asegurarse de que los promotores privados hubieran dotado a las empresas del máximo de recursos de capital que pudieran obtener. ${ }^{26}$

Esta demarcación de sus actividades estaba ausente en la ley orgánica de 1940 y expresaba, por un lado, el peso que tenían en la economía mexicana ciertos agentes del sector privado y, por otro, la búsqueda de las alianzas dominantes de impulsar la acumulación de capital sobre bases privadas. ${ }^{27}$

privado. Sin embargo, pronto los recursos privados resultaron insuficientes y NAFINSA recibió fondos del Eximbank, atados a la compra de productos de Estados Unidos, con los que suscribió acciones y extendió créditos para la nueva firma, en Blair, "Nacional", 1964.

${ }^{23}$ En la industria del papel, NAFINSA intervino en la creación de la Compañía Industrial Atenquique en 1941. En 1943 fue fundamental para la creación de Cementos Guadalajara, S. A. y contribuyó con el financiamiento de otras empresas.

${ }^{24}$ Nacional, Legislación, 1994, pp. 79-84.

${ }^{25}$ En su artículo 5, dicho decreto establecía que NAFinsa debía "dedicar sus recursos a la creación o fortalecimiento de empresas fundamentales para la economía del país", en ibid., p. 81.

${ }^{26} \mathrm{El}$ mismo decreto sostenía "[e]n todo caso, la Nacional Financiera se esforzará por obtener la cooperación privada en las promociones que emprenda y, antes de otorgar financiamientos, se cerciorará de que los promotores han dotado a las empresas del máximo de recursos de capital que razonablemente puedan obtener en las circunstancias". Ibid., p. 81.

${ }^{27}$ Véanse Nacional, Nacional, 1985, e Informes, 1934-1986, años 1940, 1947 y 1948. El propio Alemán (1946-1952), al presentarle al Congreso la nueva legislación de NAFINSA, planteó la 
Las inversiones de la institución eran amplias y diversificadas, manteniendo una posición dominante en la propiedad de varias empresas. En este sentido, el éxito de la actividad de promoción de NAFINSA entre 1941 y 1947 generó recelos en el sector privado. ${ }^{28}$ La propia institución había adquirido una visión crítica respecto de la forma en que se financiaba el sector privado, recurriendo mucho a la deuda y muy poco a los aportes de capital. Ante esto, para ciertos segmentos del sector privado NAFINSA aparecía como un fuerte competidor y un crítico no amigable. ${ }^{29}$

Sin embargo, ni el gobierno de Ávila Camacho, ni el de Alemán tenían la intención de interferir en el proceso de acumulación de capital del sector privado. Desde la década de 1930 se coincidía, entre las diferentes alianzas políticas del país, en la necesidad de favorecer la acumulación privada de capital. ${ }^{30}$ En cuanto al sistema financiero, se establecía que debía ser conducido por el sector privado y, para actividades o proyectos en los que este no podía o no quería intervenir, se diseñó toda una serie de instituciones y procesos necesarios para completar la estructura. ${ }^{31}$ Sin las particulares condiciones que generó la segunda guerra mundial, este lineamiento se expresó con más claridad en las acciones estatales y en la actuación de Nacional Financiera. ${ }^{32}$

En este sentido, durante el gobierno de Alemán se llevaron adelante considerablemente menos promociones de nuevos proyectos que en el sexenio anterior. ${ }^{33}$ Así, las actividades empresariales de NAFINSA se diluyeron paulatinamente para actuar principalmente otorgando créditos y sin involucrarse activamente en el desarrollo de las empresas. Los fondos con los que NAFINSA desplegó sus actividades en esta primera etapa fueron mayoritariamente recursos propios. Desde 1940 la institución logró un gran aumento de su capital, empujado por su buena rentabilidad y la capitalización de dividendos. Medido en dólares, el aumento de su capital

necesidad de delimitar el campo de operaciones de la institución de tal manera que no invadiera actividades que solían pertenecer a la órbita de la banca privada. Blair, "Nacional", 1964, pp. 220221. En el informe de gobierno de 1948, Alemán sostiene que Nacional Financiera limitará sus operaciones al financiamiento de industrias de interés fundamental para el país. Véase Cámara, Informes, Alemán, 2006.

${ }^{28}$ En las memorias de la institución de esos años puede verse esta preocupación por parte de sus directivos.

${ }^{29}$ Blair, "Nacional", 1964.

${ }^{30}$ Maxfield, Governing, 1990.

${ }^{31}$ Bennett y Sharpe, "State", 1982, y Maxfield, Governing, 1990.

${ }^{32}$ Por ejemplo: "De acuerdo con su política basada en el principio de estimular y fortalecer la iniciativa privada, la Nacional Financiera estuvo pronta a apoyar industrias de interés nacional que, por la magnitud de la inversión necesaria y su baja o lenta redituabilidad, no constituyen una inversión atractiva para los particulares”, en Nacional, Informes, 1934-1986, año 1953, p. 49.

${ }^{33}$ Entre ellas, una de las más significativas fue el caso de Tubos de Acero de México, en la que se combinaron capitales italianos, suecos y mexicanos. 
fue considerable, al tiempo que la institución logró rentabilidades positivas y crecientes. ${ }^{34}$ Su solidez, a su vez, le permitió emitir obligaciones para captar recursos.

En 1940 se emitieron por primera vez los títulos financieros, denominados en moneda nacional y en dólares, que eran los bonos propios del banco, garantizados con bonos federales y estatales y del Distrito Federal. Estos títulos llegaron a ser los principales valores emitidos por NAFINSA en la década de 1960. En 1941 se emitieron, a su vez, los certificados de participación, con respaldo en paquetes de acciones y bonos designados para cada emisión. La circulación de las obligaciones emitidas por Nacional Financiera fue creciente entre 1940 y 1954, explicada en su mayor parte por los certificados de participación. ${ }^{35}$

Así, en esta primera etapa la institución desplegó sus actividades principalmente con fondos provenientes de la ampliación de su capital y la emisión de obligaciones, denominados fondos propios. Además, la institución canalizaba fondos que no eran propios, como los recursos vinculados o los provenientes del exterior, que en el periodo aumentaron su participación como fuentes de recursos de NAFinsa (véase cuadro 2).

En cuanto a los recursos del exterior, el Estado mexicano acudió desde el inicio de la segunda guerra mundial al Expor-Import Bank (ExIMBANK) y, más tarde, al Banco Interamericano de Reconstrucción y Fomento (BIRF) y al Banco Interamericano de Desarrollo (BID). Gran parte de estos fondos tenía el destino preestablecido y, en muchos casos, el objetivo era financiar obras o empresas ligadas a la infraestructura económica.

En cuanto a los recursos vinculados, se trataba de la conformación de fondos a partir de recursos provenientes del gobierno federal que NAFINSA administraba y canalizaba hacia los sectores específicos contemplados en cada fondo. Entre ellos, el Fondo de Garantía y Fomento a la Industria Mediana y Pequeña (FogaIN), creado en 1953, fue uno de los más importantes.

\section{Nacional Financiera en el desarrollo estabilizador, 1955-1970}

Hacia mediados de la década de 1950 se produjo un quiebre fundamental en la economía mexicana. En 1954 se llevó adelante una importante

\footnotetext{
${ }^{34}$ Nacional, Economía, 1978.

${ }^{35}$ No es el objetivo de este trabajo analizar la participación de NAFINSA en la conformación y profundización del mercado de valores mexicano. Sin embargo, podemos señalar que en 1946, $19 \%$ de los valores que circulaban en el mercado nacional había sido emitido por NAFINSA, llegando casi a 30\% entre 1950 y 1952. Esa participación disminuyó para mantenerse entre 15 y $20 \%$ hasta mediados de la década de 1960 (Nacional, Economía, 1974).
} 
CUADRO 2. FUENTES DE RECURSOS DE NAFINSA (PORCENTAJE)

\begin{tabular}{lrrrrr}
\hline & 1941 & 1945 & 1946 & 1950 & 1954 \\
& & & & & \\
Recursos propios & 100 & 91 & 75.7 & 61.8 & 57.9 \\
Recursos no propios & & 9 & 25.3 & 38.2 & 42.1 \\
\hline
\end{tabular}

Fuente: Nacional, Informes, 1934-1986, años 1955-1957.

devaluación que marcó el fin de la inestabilidad cambiaria y de precios, iniciándose un periodo de fuerte crecimiento con estabilidad. Esta ruptura terminó de gestarse cuando, en 1958, asumió la presidencia Adolfo López Mateos (1958 a 1964). Comenzó así el periodo conocido como el desarrollo estabilizador, que coincidió con la segunda etapa de la industrialización vía sustitución de importaciones.

Para lograr la estabilidad se buscó evitar recurrir a la emisión monetaria, utilizando mecanismos para captar ahorro interno y externo. Además, este último resultaba fundamental para evitar desequilibrios en el balance de pagos, para lo cual se intentó mantener las tasas de interés atractivas para los inversores foráneos. Para captar y canalizar el ahorro interno, se utilizó intensamente el mecanismo de encajes bancarios mediante el cual el Banco de México establecía, a partir de un sistema de porcentajes, en qué tipo de activos los bancos debían invertir y prestar el dinero captado. De esta manera se aseguraba el financiamiento del Estado y de sectores productivos. La industrialización, a su vez, siguió siendo un objetivo de la estrategia económica, que poseía un anclaje desarrollista, aunque sin una política selectiva que guiara el proceso. ${ }^{36}$

En esta etapa, la dirección del financiamiento de NAFINSA siguió dominada por los sectores de infraestructura, que acentuaron su participación en el total de los recursos canalizados por la institución. Los rubros de energía eléctrica y transporte fueron los principales beneficiados por la política del banco, aumentando significativamente su participación en relación con la etapa anterior (véase cuadro 3). El sector de infraestructura, que entre 1940 y 1954 había recibido $49.8 \%$ de los recursos de la institu-

\footnotetext{
${ }^{36}$ Véase Banco, Informe, 1934-1986, años 1954-1970. Así, la política económica aplicada en esos años combinaba la ortodoxia en la búsqueda de la estabilidad de precios, como principal objetivo, y en el control de la emisión monetaria como inexcusable instrumento para lograrlo, con elementos intervencionistas, como el control selectivo del crédito y el manejo de la tasa de interés. Además, el Estado mantenía un papel activo como productor de bienes y servicios. Para una discusión de estos aspectos del desarrollo estabilizador, véase Fitzgerald, "Déficit", 1981.
} 
CUADRO 3. USO DE LOS FONDOS DE NAFINSA (PORCENTAJE)

\begin{tabular}{lcccc}
\hline Sectores & $1940-1954$ & $1955-1962$ & $1963-1970$ & $1955-1970$ \\
Infraestructura & & & & \\
$\quad$ Energía eléctrica & 49.8 & 50.0 & 67.9 & 59.0 \\
Transporte & 11.1 & 22.1 & 33.7 & 27.9 \\
Irrigación, caminos & 9.3 & 21.8 & 12.8 & 17.3 \\
$\quad$ y otras obras públicas & 29.4 & 6.2 & 21.3 & 13.8 \\
Industria & 26.7 & 37.1 & 27.3 & 32.2 \\
Básica & 13.8 & 14.9 & 8.3 & 11.6 \\
Otras de transformación & 12.9 & 20.6 & 19.0 & 20.6 \\
$\quad$ Celulosa y papel & 1.7 & 2.6 & 1.8 & 2.2 \\
$\quad$ Productos químicos & 1.9 & 3.0 & 3.7 & 3.4 \\
$\quad$ Maquinaria & 1.1 & 1.6 & 1.2 & 1.4 \\
$\quad$ Equipo de transporte & 0.2 & 6.3 & 5.1 & 5.7 \\
$\quad$ Otras & 8.3 & 8.6 & 6.2 & 8 \\
Otras actividades & 23.4 & 12.9 & 4.8 & 8.9 \\
\hline
\end{tabular}

Fuente: Nacional, Economía, 1978.

ción, pasó a obtener casi 70\% de los fondos de NAFINSA en el periodo de 1963 a 1970.

A su vez, en esta etapa, la industria básica vio reducida su participación como destino del financiamiento de Nacional Financiera, con una pronunciada caída en el subperiodo 1963-1970. Como contrapartida, aumentó la participación de otras industrias de transformación como receptoras de recursos de la institución. Dentro de ese sector, fue el rubro de equipo de transporte el que más aumentó su participación, en correspondencia con la predominancia que tuvieron las áreas de transporte y energía eléctrica como receptoras de recursos de la institución.

Esta estructura en el destino de los fondos de Nacional Financiera evidencia algunas de las características del proceso de industrialización mexicano y de la estrategia del desarrollo estabilizador. La dispersión del financiamiento al sector industrial revela la ausencia de una política sectorial y selectiva en la estrategia de industrialización. La escasa participación de la industria del papel y celulosa y de productos químicos implica que las industrias de insumos básicos, clave en la etapa por la que transitaba el proceso de ISI, no eran prioritarias en la estrategia seguida. Adicionalmente, la industria básica recibió menos de $10 \%$ de los fondos de la institución entre 1963 y 1970. 
Aun así, la labor de apoyo al sector industrial por parte de la institución fue importante y creciente. Los recursos totales volcados a la industria aumentaron progresivamente (véase cuadro 4).

Sin embargo, más allá de este crecimiento en el financiamiento al sector industrial, se observan cambios en las modalidades del mismo. Como señalamos en el apartado anterior, se fue diluyendo la labor empresarial de Nacional Financiera y, en esta etapa, el financiamiento para la promoción de la industria fue principalmente para ampliación de plantas y créditos de operación destinados a apoyar promociones emprendidas con anterioridad. En efecto, la institución apoyó técnica y financieramente la consolidación, expansión e integración de diversas empresas. ${ }^{37}$ Acorde a estas tendencias, se consolidó la utilización del crédito como forma predominante de canalización de los recursos (véase gráfica 2).

Otro hecho destacado de esta etapa, es el aumento del peso del capital extranjero en las fuentes de fondos de la institución; hacia el final de la década de 1960 los créditos del exterior explicaban más de 40\% de los recursos de NAFInSA (véase cuadro 5).

El aumento de la participación de los sectores de infraestructura en el financiamiento canalizado por Nacional Financiera debe entenderse como parte de este proceso, ya que los créditos internacionales tenían como destino principalmente empresas ligadas a estos sectores. En este sentido, la evolución de la institución expresaba las características de la economía mexicana, que en forma creciente se apoyaba en los recursos externos para sostener su funcionamiento. El destino de los fondos recibidos quedaba supeditado a las políticas llevadas a cabo por estas instituciones internacionales, aunque existiera internamente un proceso por el cual se aprobaba o declinaba cada crédito. El ExIMBANK otorgaba créditos atados que favorecían al comercio de su país. Los sectores de infraestructura eran los principales receptores de los fondos del Banco Mundial. ${ }^{38}$ De esta forma, el destino de estos créditos podía tener algún punto de contacto con los objetivos de la política nacional, aunque no era esta la que en última

${ }^{37}$ De las empresas que recibieron mayor financiamiento en las décadas de 1950 y 1960 , las más importantes fueron Ferrocarriles Nacionales de México, Altos Hornos de México, S. A., Compañía Mexicana de Luz y Fuerza del Centro, S. A. y la Comisión Federal de Electricidad (CFE). Como vemos, el sector de infraestructura se destaca a partir de la empresa de ferrocarriles y de las empresas energéticas. Estas últimas tuvieron un fuerte apoyo en la década de 1970 (sobre todo desde 1964). La CFE fue una permanente receptora de créditos de NAFINSA. La Compañía Mexicana de Luz y Fuerza del Centro recibió grandes sumas de financiamiento, producto de la mexicanización.

${ }^{38}$ El BIRF, por ejemplo, hacia finales de la década de 1950 y principios de los sesenta, otorgó cuantiosas sumas que a través de NAFINSA, eran canalizadas a empresas como la Comisión Federal de Electricidad o la Compañía Mexicana de Luz y Fuerza del Centro. En varios años, Ferrocarriles Nacionales de México y Ferrocarriles del Pacífico fueron las principales destinatarias de fondos provenientes del Eximbank. Véase Nacional, Economía, 1974. 
CUADRO 4. FINANCIAMIENTO TOTAL DE NAFINSA A LA INDUSTRIA

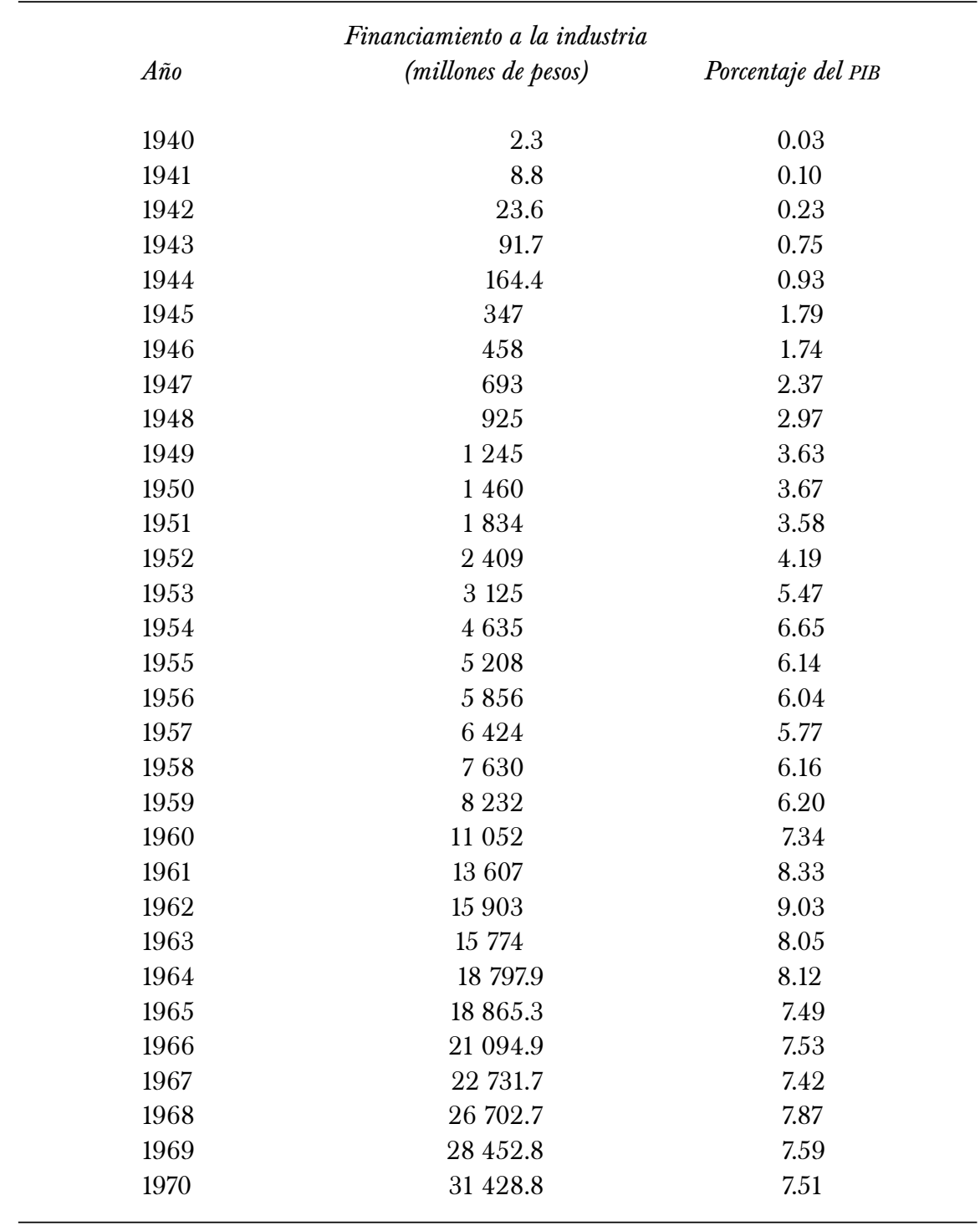

Fuente: elaboración propia con base en Nacional, Economía, 1974. 


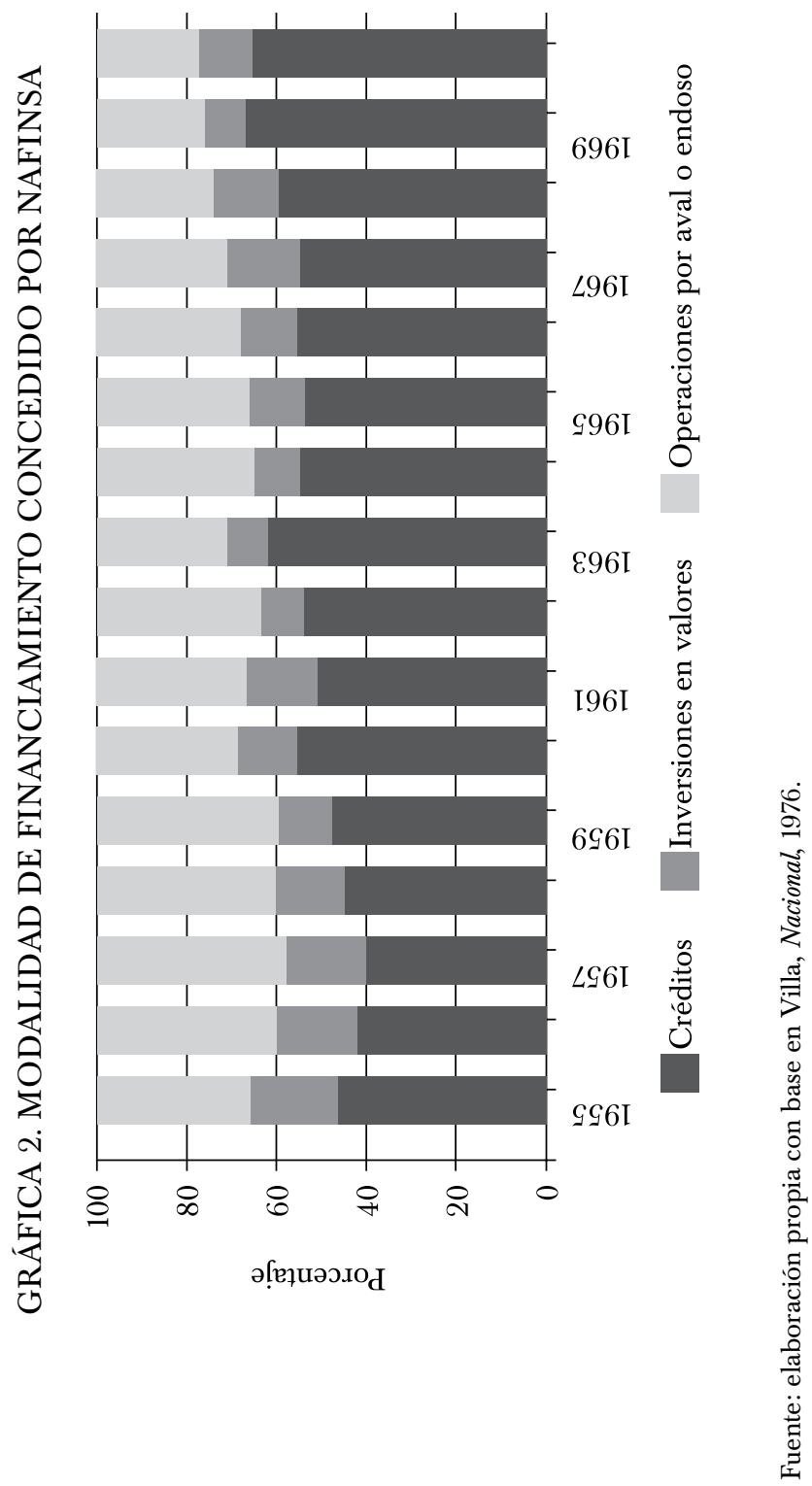


CUADRO 5. RECURSOS DE NAFINSA (PORCENTAJE)

\begin{tabular}{lrrrrrrrr}
\hline & 1952 & 1955 & 1960 & 1962 & 1964 & 1966 & 1968 & 1970 \\
& & & & & & & & \\
Recursos propios & 33.9 & 29.4 & 25.3 & 22.9 & 31.4 & 30.9 & 29.8 & 30.4 \\
Capital y reservas & 4.4 & 4.3 & 5.6 & 3.9 & 5.9 & 6.3 & 5.3 & 4.5 \\
Títulos & 29.5 & 25.1 & 19.7 & 19 & 25.5 & 24.6 & 24.5 & 25.9 \\
Recursos no propios & 66.1 & 70.6 & 74.7 & 77.1 & 68.6 & 69.1 & 70.2 & 69.6 \\
Créditos del exterior & 23.1 & 22.9 & 35.3 & 33.7 & 32.9 & 34.0 & 41.3 & 42.5 \\
\hline
\end{tabular}

Fuente: elaboración propia con base en Nacional, Informes, 1934-1986, años 1955-1972.

instancia determinaba la utilización de los recursos. Así, NAFINSA actuaba simplemente como canal de los recursos externos hacia las actividades financiadas.

A su vez, en muchas ocasiones los destinatarios finales de los créditos externos eran empresas privadas. Esta modalidad implicó un subsidio para esas empresas, ya que el banco de desarrollo asumía el riesgo cambiario. La institución quedaba endeudada en dólares con el organismo multilateral y prestaba a las empresas privadas locales, que quedaban endeudas en pesos con Nacional Financiera. ${ }^{39}$ También se avanzó en la conformación de fondos a partir de recursos vinculados. El Fogain, fondo destinado al apoyo de las pequeñas y medianas empresas, tuvo una actuación destacada desde 1954. Este fideicomiso, creado en 1953, tenía el objetivo de contribuir con las empresas pequeñas y medianas para contrarrestar los efectos de la concentración que producía el desarrollo industrial y el avance tecnológico. ${ }^{40}$ Las distintas publicaciones de Nacional Financiera destacan la actuación de este fondo y su contribución en el financiamiento a las empresas pequeñas y medianas. ${ }^{41}$

En definitiva, durante el periodo que se extiende entre 1954 y 1970, tanto el conjunto de la economía como el sector industrial lograron un crecimiento importante. ${ }^{42}$ Sin embargo, sin una política selectiva que permitiera profundizar el proceso de sustitución de importaciones se fueron

${ }^{39}$ Garrido, "Industrialización”, 2002.

${ }^{40}$ Entre sus operaciones figuraron la de garantizar a las instituciones de crédito privadas el pago de créditos que otorgaran a pequeñas y medianas empresas; tomar, colocar y suscribir obligaciones emitidas por estas empresas; apoyo técnico y asesoría en proyectos de inversión. Además, en diversos aspectos sirvió de intermediario entre las empresas y los bancos privados.

${ }^{41}$ Otros fondos creados en este periodo fueron el Fondo de Garantía y Fomento al Turismo (FonatuR), creado en 1957, y el Fondo Nacional de Estudios de Preinversión (FONEP), creado en 1967 con recursos del gobierno federal y el BID.

${ }^{42}$ Solís, Evolución, 1999. 
gestando desequilibrios que comprometían el crecimiento futuro. En este contexto, Nacional Financiera desempeñó un papel importante para el proceso de industrialización, pero, en ausencia de una estrategia selectiva de sustitución de importaciones, no contribuyó a superar las deficiencias estructurales que se agudizaban en la industria mexicana. El sesgo antiexportador, la necesidad creciente de divisas, el atraso tecnológico, etc., no eran atacados consistentemente por las herramientas de política económica creadas. $^{43}$

Si bien la estrategia económica impulsada tenía un contenido desarrollista, no existió una política certera de fomento de la sustitución de importaciones de insumos básicos y bienes de capital. A su vez, ante la política cambiaria y comercial que se ponía en práctica, el déficit comercial resultaba un dato innegable, que requería ser financiado. En contrapartida, la deuda externa crecía tanto en valores absolutos como en porcentaje del PIB. $^{44}$

Además, sin una reforma tributaria profunda, se partía de la base de la existencia de déficit público que se buscaba mantener en niveles "aceptables". ${ }^{45}$ Los déficits fiscales tenían una configuración estructural, ya que eran requeridos para mantener la estabilidad y reproductibilidad del desarrollo estabilizador, debido a que la reducida carga fiscal para las empresas, las tasas de interés subsidiadas (dada la necesidad de mantener tasas de interés reales altas para la atracción de capitales extranjeros) y los precios administrados de diversos insumos (como la energía eléctrica y los derivados del petróleo) resultaban fundamentales para la rentabilidad de las empresas, al tiempo que deterioraban los ingresos fiscales. ${ }^{46}$ De este modo,

\footnotetext{
${ }^{43}$ En cuanto al éxito o fracaso del esquema del desarrollo estabilizador, existe un importante debate en la historiografía mexicana. Si bien las tasas de crecimiento alcanzadas en esos años fueron significativas, algunos autores, ligados a una posición estructuralista, consideran que en ese esquema se fueron gestando los desequilibrios y contradicciones que se expresarían con fuerza en la década de 1970, véanse Reynolds, "Por qué", 1977; Fitzgerald, "Déficit", 1981, y Gracida y Fujigaki, "Economía", 2005, entre otros. La visión ortodoxa, en cambio, considera que fueron las políticas monetarias y fiscales laxas, del sexenio 1970-1976, las que causaron los desequilibrios de los años setenta, véanse Solís, Evolución, 1999, y Ortiz, Desarrollo, 1998. La misma postura puede encontrarse en los escritos del FMI de la década de 1970.

${ }^{44}$ Pasó de representar 6\% del PIB en 1958, a representar 19\% en 1970. En el mismo lapso las exportaciones perdían peso en el PIB, pasando de 7\% del PIB a 4\% en el mismo lapso. Véase The Montevideo Oxford Latin American Economic History Database, Programa de Historia Económica y Social-Universidad de la República, Montevideo, Uruguay/Department of International Development-Oxford University, en $\langle$ http://oxlad.qeh.ox.ac.uk〉. [Consulta: 14 de enero de 2011.]

${ }^{45}$ Esta situación se debía a la existencia de un sistema tributario que imponía cargas muy bajas al sector empresario y todo tipo de exenciones y subsidios, que generaban una raquítica base de ingresos públicos. Al respecto véanse Kaldor, "Reformas", 1973; Reynolds, "Por qué”, 1977, e Izquierdo, Politica, 1995, entre otros.

${ }^{46}$ Garrido, “Industrialización”, 2002.
} 
el déficit fiscal resultaba necesario en el esquema del desarrollo estabilizador para asegurar la rentabilidad de las empresas privadas y la consecuencia necesaria era el endeudamiento público, tanto interno como externo.

A estos desacoples macroeconómicos, se sumaban otros desequilibrios socioeconómicos, como la creciente concentración del ingreso y los problemas en el mercado laboral, ${ }^{47}$ que hacia finales de la década de 1960 generaban un progresivo descontento popular y una pérdida de legitimidad en el esquema de política económica que había mantenido la estabilidad cambiaria y de precios desde la década de los cincuenta.

\section{Los años de Echeverría y López Portillo: hacia la crisis de la deuda: 1971-1982}

En la década de 1970 la política económica mexicana experimentó un cambio fundamental: la estrategia de estabilización, fuertemente cuestionada, cedió su lugar a políticas expansivas con el objetivo de apuntalar la demanda agregada y aumentar así el nivel de empleo. El financiamiento público con emisión monetaria, restringido en el periodo anterior, volvió a adquirir un papel importante. Además, se puso fin a 20 años de estabilidad cambiaria cuando en 1976 se produjo una fuerte devaluación abandonándose la paridad que regía desde 1954 .

En relación con el proceso de industrialización en curso, en esta etapa se buscó acelerar la sustitución de importaciones en los sectores productores de insumos básicos y bienes de capital. Como resultado de dichos lineamientos, el Estado incrementaría notablemente su intervención directa en la producción de bienes y servicios, sobre todo en ramas básicas.

En estas condiciones, durante la presidencia de Echeverría (1970-1976) se produjo un nuevo cambio en las modalidades de intervención de NAFINSA, que se plasmaron en la sanción, en 1975, de una nueva ley orgánica en donde se enfatizaba la necesidad de fomentar el desarrollo de la producción de bienes de capital e insumos estratégicos. ${ }^{48}$

En cuanto al destino de sus recursos, en correspondencia con la estrategia de profundización del proceso de sustitución de importaciones se produjo, entre 1971 y 1976, un aumento en la participación del sector industrial en el financiamiento total concedido por la institución, explicado por un crecimiento significativo de las industrias básicas. Como contrapartida, el sector infraestructura registró un peso decreciente (véase cuadro 6). Durante la presidencia de López Portillo (1976-1982) se profundizó esta orientación, siendo muy significativo el incremento de la participación del

${ }^{47}$ Reynolds, "Por qué", 1977.

${ }^{48}$ Véase Nacional, Legislación, 1994, pp. 115-126. 
sector de industrias básicas en detrimento del sector de infraestructura. Estos números eran expresión del aumento del peso del Estado, a través del banco de desarrollo, en la industria siderúrgica y la industria petrolera.

La nueva orientación de las actividades de NAFINSA se expresó también en su creciente participación en la administración y propiedad de empresas. La institución emprendió, entre 1970 y 1982, numerosos proyectos industriales, y se hizo cargo de diversas empresas ya existentes. ${ }^{49}$

El grupo de empresas de NAFINSA estaba conformado por 74 empresas en 1977, mientras que en 1981 ese número se había elevado a 94. Es decir, en esos años la institución creó 20 empresas, quince de ellas entre 1979 y 1981. En su mayoría eran compañías pertenecientes al sector industrial, como lo evidencia el hecho que el Grupo Industrial NAFIN, que en 1964 estaba conformado por 47 empresas, poseía 69 en 1977 y 88 en 1981. Se trataba de compañías de los sectores siderúrgico, petroquímico y de bienes de capital (véase cuadro 7$).{ }^{50}$

A su vez, desde la segunda mitad de la década de los setenta, en la medida en que muchas empresas sufrieron problemas financieros, NAFINSA buscó socorrerlas por las consecuencias que esto generaba para los inversores privados y en términos de empleo. Esta actitud estaba en línea con el deseo general por parte del Estado de auxiliar a empresas del sector privado que estaban a punto de quebrar. ${ }^{51}$ Así, mantener el nivel de empleo y profundizar el proceso de industrialización fueron las motivaciones de la intervención estatal en este periodo que, en muchos casos, tomó la forma de apropiación directa de las empresas. ${ }^{52}$

Esta proliferación en las actividades de promoción industrial de NAFINSA estuvo acompañada por un crecimiento en las fuentes propias de recursos, aunque estas fueron perdiendo dinamismo hacia el final de la década de los setenta. Esto ocurrió tanto con la colocación de obligaciones en el mercado interno como con las utilidades generadas por la institución. Estas últimas se redujeron considerablemente en los últimos años de esa

${ }^{49}$ En la nueva ley orgánica de 1975 estaba ausente la insistencia en limitar el ámbito de actuación de la institución de tal manera que no interfiriera en los negocios privados, que había sido fundamental en el decreto de 1947 que reformó la ley orgánica de 1940.

${ }^{50}$ Ramírez, Development, 1986. Uno de los proyectos más importantes impulsados por el Estado en estos años y en el que NAFINSA tuvo una participación importante, fue Siderúrgica Lázaro Cárdenas-Las Truchas, S. A. Este proyecto le dio al Estado un papel protagónico en el sector siderúrgico. A su vez, entre 1977 y 1981, impusló catorce proyectos vinculados a la producción de bienes de capital.

${ }^{51}$ Bennett y Sharpe, "State", 1982. Desde 1970 se amplió enormente el espectro de empresas estatales sin una clara racionalidad en la conformación de nuevas empresas o en la absorsión de algunas ya existentes, que estaban en manos del sector privado. Mientras que entre 1955 y 1970 llegaron a existir 272 empresas paraestatales, entre 1970 y 1982 ese número crecería a 1155 . Marichal, "Auge", 2003.

${ }_{52}$ Véanse los informes presidenciales de López Portillo en Cámara, Informes, López Portillo, 2006. 
CUADRO 6. USO DE LOS FONDOS NAFINSA SEGÚN SECTOR (PORCENTAJE)

\begin{tabular}{lcccccccc}
\hline & $1963-$ & $1970-$ & & & & & & $1979-$ \\
& 1970 & 1976 & 1979 & 1980 & 1981 & 1982 & 1983 & 1983 \\
& & & & & & & & \\
Infraestructura & 67.9 & 60.9 & 55.7 & 55 & 45.6 & 20 & 20.5 & 39.4 \\
Industria & 27.3 & 35.5 & 28.4 & 29 & 32.4 & 54.1 & 54 & 39.6 \\
$\quad$ Básica & 8.3 & 17.4 & 16.7 & 17 & 23.1 & 41.8 & 41.4 & 28 \\
$\quad$ Otras & 19 & 18.1 & 11.7 & 12 & 9.3 & 12.3 & 12.6 & 11.6 \\
Otras Actividades & 4.8 & 3.6 & 15.9 & 16 & 22 & 25.9 & 25.5 & 21 \\
\hline
\end{tabular}

Fuente: elaboración propia con base en Nacional, Economía, 1978, y Ramírez, Development, 1986.

CUADRO 7. GRUPO DE EMPRESAS Y GRUPO INDUSTRIAL NAFIN

\begin{tabular}{lcccccc}
\hline & 1977 & 1978 & 1979 & 1980 & 1981 & 1982 \\
& & & & & & \\
Grupo de Empresas NAFIN & 74 & 76 & 79 & 87 & 94 & 94 \\
Grupo Industrial NAFIN & 69 & 71 & 73 & 81 & 88 & 88 \\
\hline
\end{tabular}

Fuente: elaboración propia con base en Nacional, Informes, 1934-1986, años 1977-1982.

década. Por su parte, el capital de la institución se incrementó medido en pesos, aunque la devaluación de 1976 generó una caída pronunciada del mismo medido en dólares. ${ }^{53}$

A su vez, se produjo un gran crecimiento de la participación de los recursos provenientes de fuentes no propias de la institución. Efectivamente, la expansión de las actividades empresariales del Estado, y de Nacional Financiera, se apoyó progresivamente en el endeudamiento externo (véase gráfica 3).

${ }^{53}$ Véanse Nacional, Economía, 1978, y Nacional, Informes, 1934-1986, años 1970-1983. 


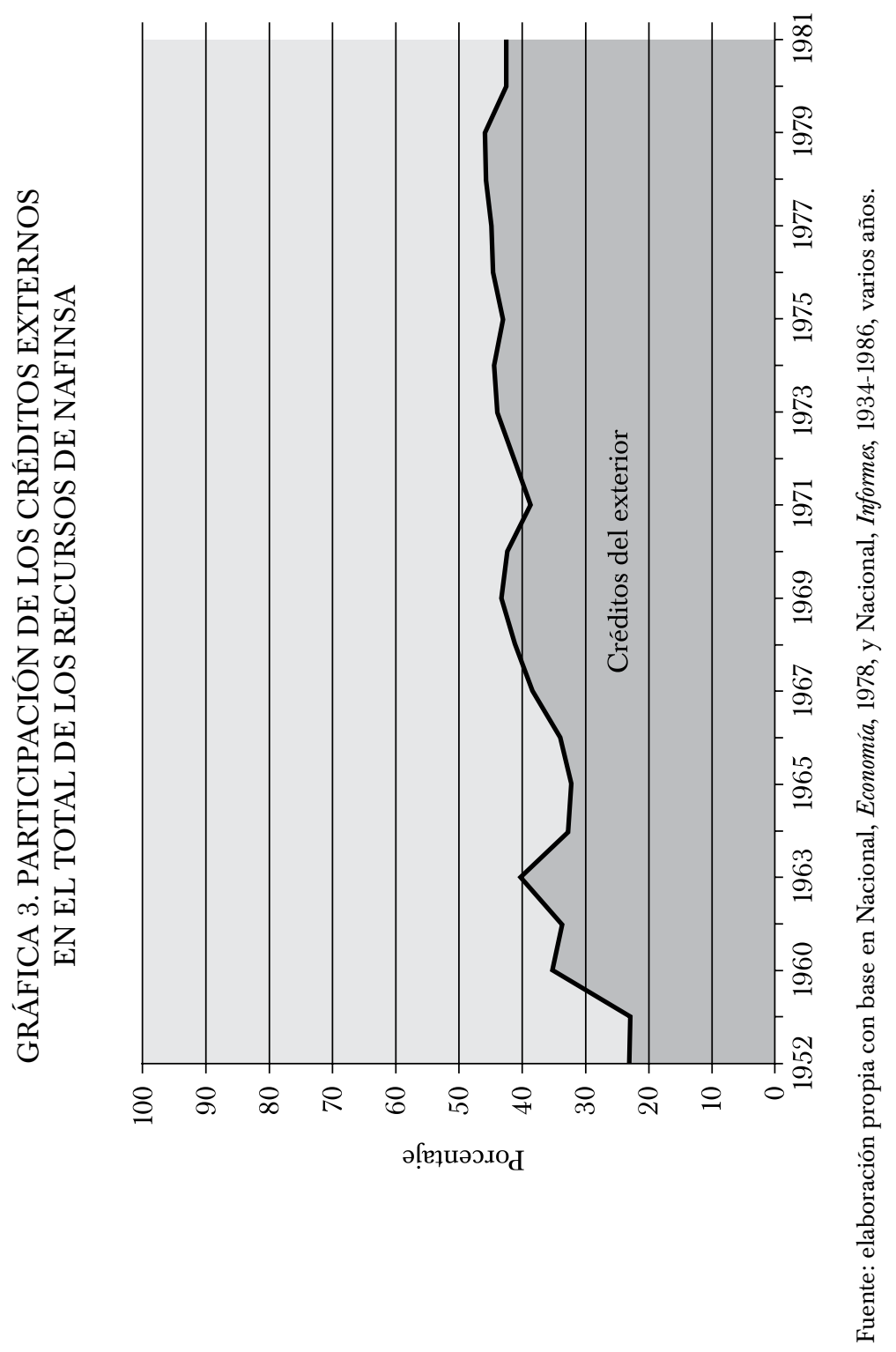


La institución siguió captando importantes recursos de agencias y bancos internacionales y su deuda externa creció entre 1979 y 1981 en 25\%, y entre ese año y 1983 en 49\%, a partir, principalmente, de créditos directos a largo plazo. ${ }^{54} \mathrm{~A}$ lo largo de la década de los setenta, los fondos provenientes de créditos del exterior explicaron más de $40 \%$ de los recursos movilizados por la institución.

Esta dinámica se insertaba en un esquema en el que la falta de dinamismo de las exportaciones, las crecientes cargas de los servicios de la deuda y las particulares condiciones internacionales, engrosaban los déficits de la cuenta corriente. En un conexto de gran liquidez en los mercados financieros mundiales, la creciente deuda externa permitía financiar dichos desequilibrios.

Sin embargo, la dinámica explosiva de la deuda y el cambio en las condiciones internacionales confluyeron, en 1982, en el estallido de la crisis de la deuda. ${ }^{55}$ Ante la crisis en la que se vio inmersa la economía mexicana, las actividades de promoción desarrolladas por NAFINSA se detuvieron completamente, mientras se inició una etapa caracterizada por un paulatino retiro del Estado de las actividades productivas y por la aplicación de políticas restrictivas, condicionado por las exigencias para la resolución del conflicto de la deuda externa. ${ }^{56}$

En los años restantes de la década de los ochenta, la institución desempeñó un papel importante como representante de México ante los acreedores internacionales. ${ }^{57}$ Fue a través de ella que el país siguió recibiendo fondos del exterior entre 1983 y el final de la década. Por lo demás, la importancia del banco fue declinante. Se desprendió de sus empresas industriales, eliminándose por completo su papel como promotor de la industria. En este sentido la ley orgánica de 1986 restringió las actividades de Nacional Financiera estableciendo que no debía participar en la promoción de proyectos industriales y que su participación en el capital de empresas industriales debía ser temporario y minoritario. ${ }^{58}$ En este contexto, no es de extrañar que de las 88 firmas que conformaban el Grupo Industrial en 1982, en 1991 quedaran sólo 32.

${ }^{54}$ Véase Ramírez, Development, 1986.

${ }^{55}$ La deuda externa mexicana, que había despegado en la década de 1960, adquirió una dinámica explosiva en los setenta. El endeudamiento externo público de México pasó de aproximadamente 7000 millones de dólares en 1970 a más de 85000 millones en 1982.

${ }^{56}$ Véase Clavijo, Reformas, 2000.

${ }^{57}$ Ares, "Estado", 2007.

${ }^{58}$ Nacional, Legislación, 1994, pp. 169-188. 


\section{LAS CONTRIBUCIONES DE NAFINSA AL FINANCIAMIENTO DE LA ISI Y SU VÍNCULO CON LA POLÍTICA ECONÓMICA}

Apelando a una mirada de largo plazo, puede sostenerse que el objetivo de contribuir al financiamiento del proceso de industrialización y, por ese medio, al desarrollo económico de México, se mantuvo como eje rector de la actuación de NAFINSA desde la década de los cuarenta hasta 1982. En una etapa de fuerte avance económico e industrial para el país, creció intensamente el financiamiento canalizado por la institución a la actividad económica (véase gráfica 4), siendo una pieza importante del proceso de industrialización vía sustitución de importaciones de México. En relación con el tamaño de la economía, el financiamiento total canalizado por NAFINSA a la actividad económica como porcentaje del PIB tuvo un aumento constante hasta 1954, cuando alcanzó 8\% (véase gráfica 5).

En la etapa del desarrollo estabilizador, el comportamiento fue ambiguo. Luego de un estancamiento entre 1954 y 1960, se produjo un importante crecimiento, alcanzándose un valor cercano a 12\% en 1962. En los años siguientes la participación de los recursos canalizados por NAFINSA en el PIB disminuyó, para retomar el sendero del crecimiento en la década de los setenta. Un comportamiento similar tuvo el financiamiento de NAFINSA en relación con el financiamiento total del sector bancario a la industria (véase gráfica 6). Este aumentó hasta explicar 50\% del financiamiento a la industria promediando la década de 1950. Luego, en los años del desarrollo estabilizador, la participación de Nacional Financiera disminuyó ante el aumento en la importancia de las instituciones financieras privadas. En la década de los setenta, los fondos canalizados por NAFINSA volvieron a ganar peso en el financiamiento bancario a la industria.

Esta información expresa que, si bien se mantuvo el lineamiento de favorecer el desarrollo industrial durante el desarrollo estabilizador, la importancia relativa de la institución, como fuente de financiamiento para el sector manufacturero, fue declinante. Esto ocurrió al tiempo que se diluyó su papel empresario y de promoción industrial, mientras se producía un crecimiento en el peso del sector infraestructura en la política de la institución. Ahora bien, ¿̇cuáles fueron las causas de ese comportamiento? A partir de lo expuesto en los apartados precedentes, surgen algunas claves al respecto.

Por un lado, luego de la segunda guerra mundial la necesidad de avanzar en obras de infraestructura ligadas al transporte y a la energía eléctrica se volvía prioritaria para el sector industrial, debido a los cuellos de botella que trababan el avance de la industria. Por otro lado, esta transformación en el carácter de NAFINSA está relacionada con el objetivo general de los gobiernos mexicanos de ese periodo de favorecer el proceso de acumula- 


\section{GRÁFICA 4. TOTAL DE FINANCIAMIENTO \\ CANALIZADO POR NAFINSA \\ (EN MILLONES DE DÓLARES)}

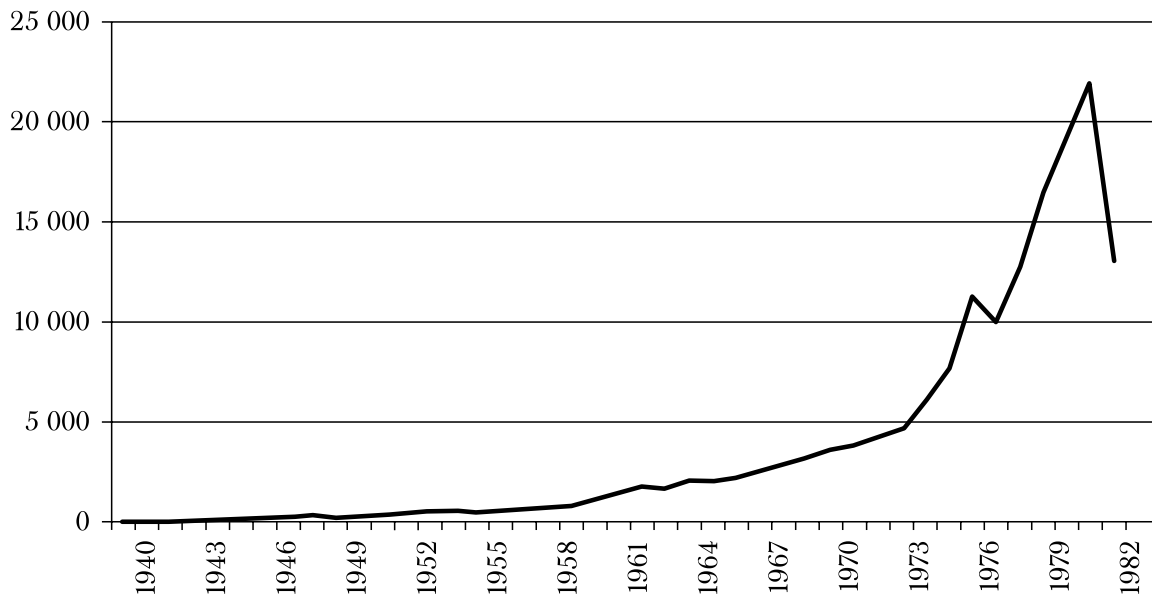

Fuente: elaboración propia con base en Nacional, Informes, 1934-1986, años 1940-1986.

\section{GRÁFICA 5. TOTAL DE FINANCIAMIENTO CANALIZADO POR NAFINSA (COMO PORCENTAJE DEL PIB)}

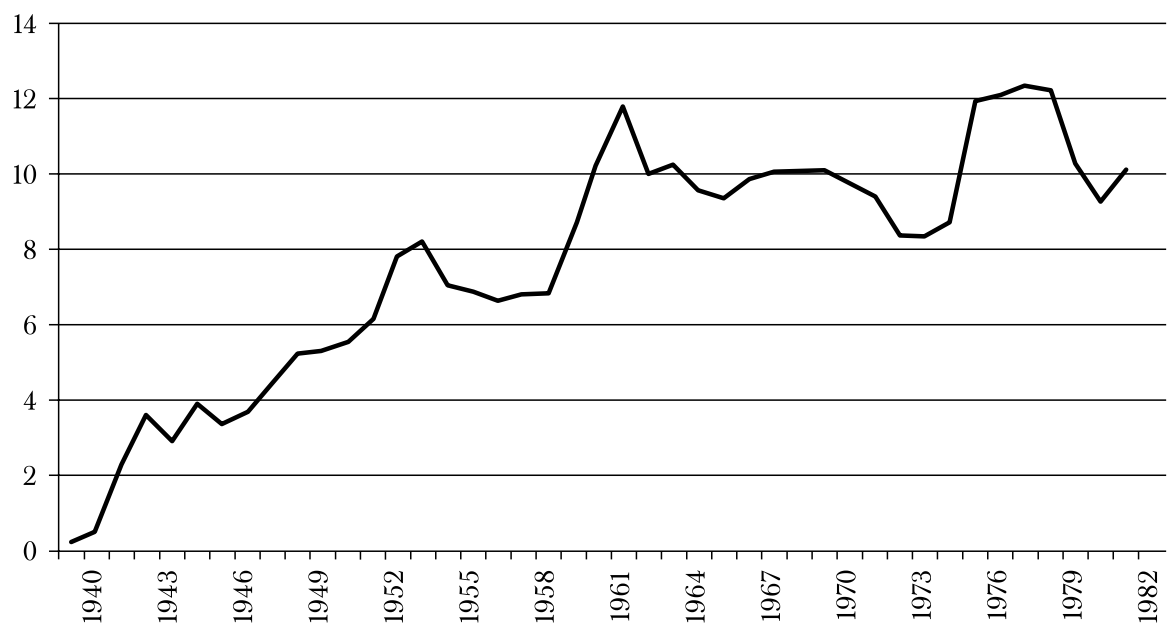

Fuente: elaboración propia con base en Nacional, Informes, 1934-1986, años 1942-1986. 
GRÁFICA 6. FINANCIAMIENTO TOTAL DEL SISTEMA BANCARIO A LA INDUSTRIA

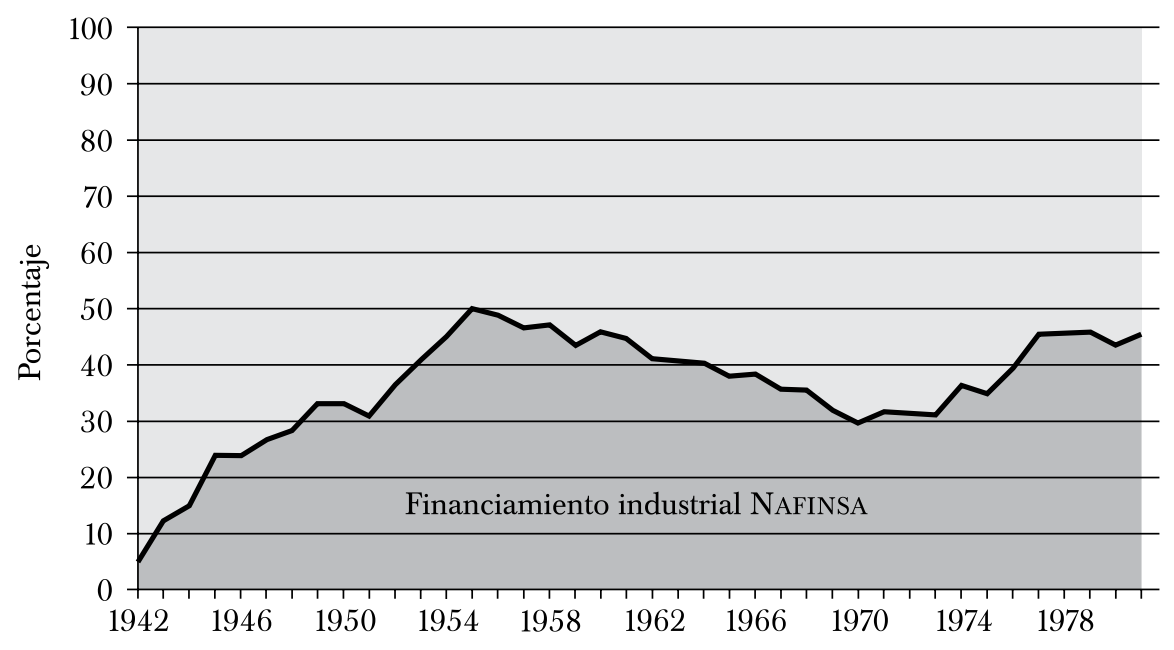

Fuente: elaboración propia con base en Nacional, Informes, 1934-1986, años 1950-1986.

ción privada de capital. El sector privado debía convertirse en el principal inversor en la economía y las instituciones públicas debían apoyar ese proceso, actuando activamente sólo donde la iniciativa privada resultara escasa o deficiente. Otro elemento importante es el peso que adquirió el capital extranjero en las fuentes de recursos de la institución y los condicionantes que ello implicó para la asignación de los fondos.

Sin embargo, es necesario incorporar otras consideraciones para terminar de comprender el carácter de NAFINSA. Mientras el financiamiento de la institución se volcaba progresivamente a empresas ligadas a energía y transporte y la institución perdía peso en el financiamiento al sector industrial, la inversión pública seguía el mismo camino. Esta se concentraba progresivamente en infraestructura, energía y comunicaciones, mientras que la participación del Estado en la formación bruta de capital fijo de la economía se incrementó hasta alcanzar 70\% en 1958, para luego disminuir progresivamente. En 1970 esta participación era de sólo 35\% (véase cuadro 8).

A partir de esto no puede concluirse necesariamente que el papel del Estado como promotor del desarrollo y la industrialización haya desaparecido. En efecto, durante el desarrollo estabilizador la política económica que se desplegó, si bien tuvo un componente ortodoxo, mantuvo una 
CUADRO 8. PARTICIPACIÓN DEL ESTADO EN LA FORMACIÓN BRUTA DE CAPITAL FIJO (1950-1970)

\begin{tabular}{lccccccc}
\hline Año & Porcentaje & Año & Porcentaje & Año & Porcentaje & Año & Porcentaje \\
& & & & & & & \\
1950 & 58 & 1956 & 72 & 1961 & 58 & 1966 & 31 \\
1951 & 64 & 1957 & 70 & 1962 & 57 & 1967 & 36 \\
1952 & 64 & 1958 & 70 & 1963 & 55 & 1968 & 36 \\
1953 & 63 & 1959 & 68 & 1964 & 55 & 1969 & 36 \\
1954 & 61 & 1960 & 65 & 1965 & 30 & 1970 & 35 \\
1955 & 66 & & & & & & \\
\hline
\end{tabular}

Fuente: Ares, "Estado", 2007.

orientación desarrollista comprometida con el crecimiento del producto y el desarrollo de la industria.

En el caso de NAFINSA, si bien su participación en el financiamiento total volcado a la industria por el sector bancario disminuyó, el sector industrial se benefició ampliamente de la política de la institución. Además del financiamiento otorgado a las más diversas ramas industriales, el financiamiento a empresas de ferrocarriles, energéticas y de bienes intermedios básicos benefició al sector industrial más allá de los propios recursos involucrados en ese tipo de operaciones.

Ahora bien, la menor participación de NAFINSA en el financiamiento total volcado a la industria y la disminución de la participación del Estado en la formación bruta de capital, tuvo como contrapartida el aumento en el peso en la economía mexicana del sector financiero privado en las décadas de los cincuenta y setenta.

En efecto, el sector financiero privado desempeñaba un papel central en el esquema del desarrollo estabilizador. Debía generar los recursos que, a través del encaje legal, el Estado utilizaba para direccionar el crédito y para financiarse sin recurrir a emisión monetaria ni a la aplicación de una reforma fiscal que permitiera incrementar la recaudación. ${ }^{59}$ Esta intervención del Estado en el destino de los recursos captados por instituciones privadas tenía su contraparte, dándole viabilidad a la política de encajes, en la concentración de un sector bancario con estrechas relaciones

\footnotetext{
${ }^{59}$ Según Fitzgerald existía un acuerdo tácito entre los bancos y la Secretaría de Hacienda para financiar cierto déficit fiscal con la condición de que no hubiera reforma fiscal. Véase Fitzgerald, "Déficit", 1981.
} 
de propiedad con el sector privado industrial. ${ }^{60}$ Se trataba de un proceso que había comenzado en las décadas de los treinta y cuarenta, con la conformación de grupos integrados por bancos, financieras y empresas industriales ${ }^{61}$ Estas relaciones son cruciales para comprender las prácticas crediticias en México. ${ }^{62}$ Los bancos comerciales emergían del interior de grupos de empresarios que evolucionaron en grupos de negocios y, luego, en conglomerados.

La concentración del sector bancario y su estrecho vínculo con el sector industrial no podía sino afectar la asignación de los créditos, ya que las empresas vinculadas a esos grupos eran las principales receptoras de financiamiento. A través de la política de encajes, el gobierno buscó romper con esta lógica sin separar a los grupos ni combatir la concentración del mercado. Sin embargo, el control estatal sobre los créditos era sólo parcial (por ejemplo, se establecía la distribución por sectores), generándose un sistema que favorecía largamente a los bancos. Así, las empresas pertenecientes a estos grupos tenían acceso a financiamiento a largo plazo.

A su vez, estos grandes conglomerados se beneficiaban de la protección contra la competencia extranjera, las exenciones de impuestos y los precios controlados de insumos y servicios públicos, y presionaban constantemente para reducir el ámbito de actuación del sector público en la industria. En efecto, en la actividad de promoción industrial, NAFINSA debía contender con un sector privado que requería permanente seguridad sobre el ámbito de actuación de las instituciones públicas y la no interferencia de ellas en los dominios privados.

El esquema del desarrollo estabilizador planteaba límites importantes para las actividades de promoción del banco de desarrollo. En ausencia de una reforma fiscal que permitiera ampliar la base de ingresos públicos y ante la prioridad otorgada al combate de la inflación que impedía la emisión monetaria, la institución, al igual que el conjunto de la economía mexicana, estaba forzada a financiarse crecientemente con fondos del exterior, cuyos destinos estaban en gran medida preestablecidos. A su vez,

${ }^{60}$ La conformación de grandes conglomerados y la creciente concentración de la economía mexicana en este periodo es un proceso bastante trabajado por la historiografía económica. Al respecto véanse Goldsmith, Financial, 1966; Gómez, "Estructura", 1975; González, Algunos, 1981; Maxfield, Governing, 1990; Garrido, "Industrialización”, 2002, y Ángel, Paradoxes, 2002, entre otros.

${ }^{61}$ Ya en 1966, Goldsmith hizo notar que media docena de bancos comerciales concentraban cuatro quintas partes de los activos de todos los bancos comerciales. Además, los mayores bancos comerciales controlaban la mayoría de las más grandes sociedades financieras, concentrando dos tercios de los activos de ese tipo de instituciones. Véase Goldsmith, Financial, 1966.

${ }^{62}$ Ángel, Paradoxes, 2002. Según el autor, estas relaciones entre firmas financieras y no financieras comenzaron como una forma de superar la escasa organización del sistema financiero en la década de 1930. A su vez, como los bancos podían prestar a corto plazo y las financieras a largo plazo, los primeros absorbían a las segundas o fundaban sus propias financieras. 
la necesidad del sector público de recurrir al financiamiento privado le impedía limitar el poder de un sector privado que crecía en concentración y que abogaba por limitar el papel empresarial del sector público.

En un contexto semejante, la capacidad de Nacional Financiera para actuar en contra de estas tendencias resultaba muy limitada, siendo que se trataba de una institución clave para el despliegue de la política económica. ${ }^{63}$ De esta manera, la contribución de NAFINSA al financiamiento del sector industrial, si bien importante, se vio limitada y fue decreciente durante ese periodo. Como alternativa, se desarrollaron canales privados para el financiamiento a largo plazo, aunque sólo accesible para ciertas empresas ligadas a los sectores más concentrados de la economía. En la década de los setenta, esas tendencias se revirtieron y NAFINSA volvió a desempeñar un papel empresarial activo y a tener un peso creciente en el financiamiento de la industria, aunque sin una clara racionalidad en su intervención y en el marco de una economía que acumulaba desequilibrios.

En este contexto, si bien Nacional Financiera logró cierta continuidad y coherencia en sus acciones, no escapó a esa lógica general y, así como encarnaba la política industrial del país, adolecía de las deficiencias de esa estrategia.

El capital extranjero tenía un peso creciente en la economía y en las fuentes de recursos de NAFINSA, sin que se establecieran criterios para definir sus ámbitos de actuación. El sector privado, por su parte, incrementaba su concentración, sin avanzar en la solución de los desequilibrios del proceso de industrialización y limitando las posibilidades de acción de instituciones nacionales como Nacional Financiera.

Aun así, es evidente que la institución adquirió un gran peso en la economía mexicana y en su desarrollo industrial, constituyéndose en un verdadero banco de desarrollo. Los recursos movilizados crecieron en relación con el PIB y, desde 1960, se mantuvieron por encima de 8\%. A su vez, entre 1950 y 1980 NAFINSA fue responsable, en promedio, de $40 \%$ del financiamiento bancario a la industria.

Ese desempeño se explica, en parte, por la continuidad en la estrategia de industrialización seguida en México. Si bien entre 1955 y 1970 la política económica priorizó la estabilidad y abandonó criterios de industrialización selectiva, nunca dejó de lado el objetivo general de desarrollar el sector manufacturero. Dicha continuidad se reflejó en las altas tasas de crecimiento del producto y del producto industrial de la economía mexicana en todo el periodo considerado.

${ }^{63}$ Blair, "Nacional”, 1964. 
A su vez, la dinámica institucional de Nacional Financiera estuvo caracterizada por una notable estabilidad, resultando en uno de los factores explicativos de su desempeño.

Entre 1936 y 1970 se sucedieron al frente de la institución sólo tres directores generales.$^{64} \mathrm{El}$ consejo directivo de la institución se componía de miembros elegidos por el gobierno federal y miembros elegidos por los accionistas privados. Esto último fue un factor importante para la adopción, por parte del banco, de prácticas conformes, en cierta medida, a las de la banca privada. En efecto, una de las recurrentes críticas del sector privado a las actividades de NAFINSA era su comportamiento "demasiado" similar al de dicho sector, ya que obtenía ganancias, mantenía una cartera "sana" de activos y se expandía constantemente con cierta coherencia y selectividad. ${ }^{65}$ La institución mantuvo, a lo largo de todo el periodo, una rentabilidad positiva, aunque hacia el final de la década de 1970, a medida que se ampliaban sus actividades de promoción y se reducía su capacidad para generar recursos propios, esta se redujo significativamente (véase gráfica 7). ${ }^{66}$

En el ámbito interno, la institución contó con una dotación de cuadros técnicos con una sólida formación. Los directores generales tuvieron el perfil del burócrata-político formado en economía o derecho ${ }^{67}$ Además, existía personal de alta calidad y la permanente atracción de importantes cuadros formados en cuestiones bancarias y financieras, que gozaron de una gran estabilidad en sus cargos. Esto se reflejó en los objetivos generales de la institución y en la continuidad de sus políticas.

Se observa, a su vez, una estrecha relación entre Nacional Financiera y otras instituciones del sector público. Su política estuvo siempre condicionada por la cercana supervisión del Banco de México y la Secretaría de Hacienda. Este entrelazamiento no funcionaba unilateralmente, evidenciándose cierta coordinación y participaciones cruzadas en las instituciones públicas más importantes dentro del Estado mexicano. Así, los máximos responsables de NAFINSA y del Banco de México eran miembros, a su vez, del consejo de directores de la otra institución. Además, la institución siempre estuvo receptiva a la iniciativa y oposición del sector privado. Este tenía representación en el consejo de la institución. La relación con el sector privado, así y todo, no estaba libre de roces y confrontaciones.

\footnotetext{
${ }^{64} \mathrm{Al}$ respecto puede verse Nacional, Economía, 1974.

${ }^{65}$ Blair, "Nacional", 1964, p. 233.

${ }^{66}$ Recordemos que el objetivo de un banco de desarrollo público no es maximizar las ganancias, sino otros objetivos ligados al desarrollo. Por tanto no puede evaluarse su desempeño a partir de las medidas de rentabilidad privada.

${ }^{67}$ Véanse, por ejemplo, Blair, "Nacional”, 1964, y Ares, "Estado", 2007.
} 
GRÁFICA 7. UTILIDADES SOBRE EL ACTIVO (ROE)

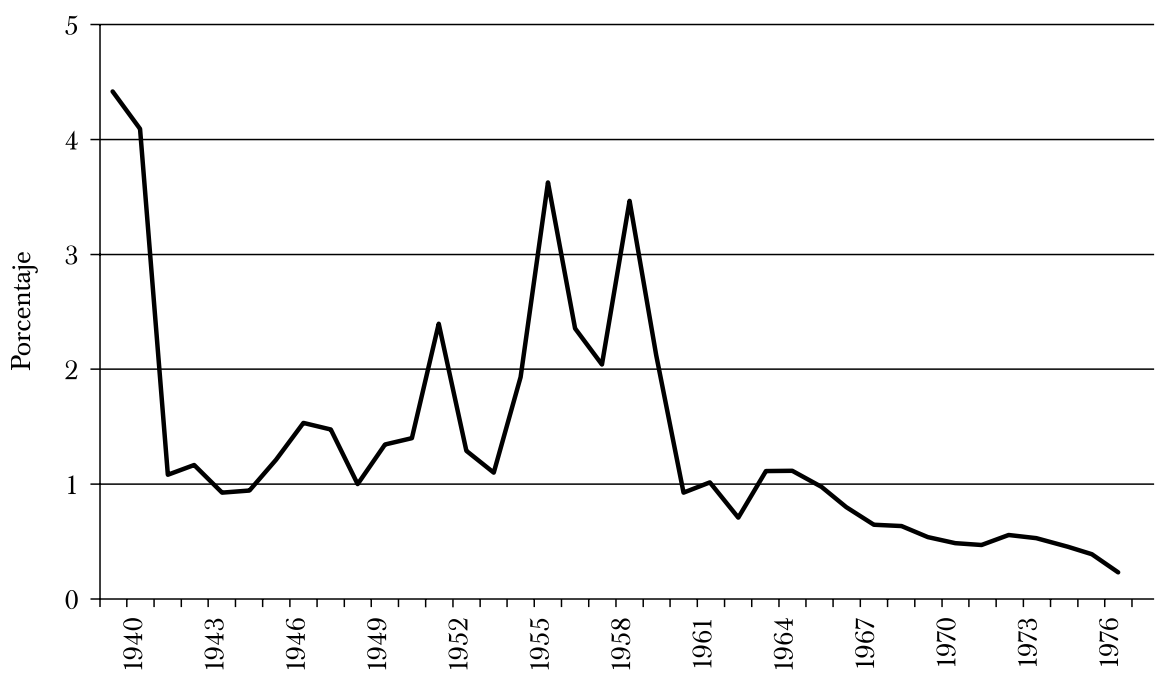

Fuente: elaboración propia con base en Nacional, Economía, 1978.

El cambio de rumbo en la política económica mexicana en 1970 se tradujo en una mayor inestabilidad en el ámbito institucional. Hasta 1982 se sucedieron seis secretarios de Hacienda, y en NAFINSA cinco directores generales. Estas sucesiones implicaron continuos cambios en la dirección de la institución, tornando más frágil su desempeño. Se trataba, en su mayoría, de dirigentes que no eran extraídos de las filas de la propia institución, por lo que resultaba compleja su identificación con los objetivos de la misma, al tiempo que afectaba la respuesta del personal hacia ellos. Más allá de las prioridades del proceso de industrialización vía sustitución de importaciones, el objetivo de mantener o ampliar el empleo llevó al Estado y a NAFINSA a hacerse cargo de muchas empresas que no siempre tenían una lógica dentro del proceso de industrialización. Aun así, importantes promociones en el área de la industria básica se llevaron adelante en este periodo.

\section{CONSIDERACIONES FINALES}

Mientras los bancos nacionales de desarrollo se extendían en todo el territorio latinoamericano, México se constituyó, a partir principalmente de 
la actuación de NAFinsA, en el país (junto a Brasil) en el cual este tipo de instituciones financieras para el desarrollo más avance e importancia han tenido. El crecimiento de NAFINSA en cuanto a fuentes de recursos y montos otorgados a diferentes sectores fue continuo entre 1940 y 1982, convirtiéndose en un agente importante del proceso de industrialización mexicano y en un participante clave del sistema financiero.

El buen desempeño y avance de la institución en este sentido puede atribuirse a diferentes factores. Entre ellos, la estabilidad institucional que caracterizó a México en todos estos años se reflejó en las capacidades organizativas de NAFINSA. Además, se trataba de una institución, junto con la Secretaría de Hacienda y el Banco de México, clave para el despliegue de la estrategia económica.

Sin embargo, de ese entramado institucional nacen también las más importantes limitaciones de la institución, ya que los recursos que canalizaba quedaban enmarcados en el esquema de política económica desplegado por la Secretaría de Hacienda y el Banco de México. Durante el desarrollo estabilizador, dicha política estaba abocada a la estabilidad cambiaria y de precios, pero no definía criterios claros y selectivos para dirigir el desarrollo industrial, quedando la política de Nacional Financiera regida por generalidades que no estaban apoyadas en planes concretos. Entre 1970 y 1982, si la estrategia económica buscó profundizar selectivamente el proceso de industrialización, lo hizo sin una clara racionalidad en ese sentido y apoyada en la creciente deuda externa.

En este sentido, la política de la institución adoleció de las mismas deficiencias que el resto de la estrategia industrial desplegada por los gobiernos mexicanos en esos años. Se había trazado una estrategia muy general, que se desarrollaba a partir de políticas dispersas y coyunturales, pero sin una política explícita de desarrollo a largo plazo. Más aún, la política económica no daba respuestas a las tensiones que se acumulaban, sobre todo desde mediados de la década de los sesenta, y que se expresarían con fuerza en la década siguiente.

Así, el Estado y sus instituciones estuvieron limitados por la necesidad de asegurar y afianzar el funcionamiento de la economía de mercado. Como muestra la experiencia de los países que se industrializaron tardíamente, en este tipo de procesos el mercado difícilmente genera la coordinación de inversiones que posibilita el desarrollo del sector manufacturero, vital para alcanzar el desarrollo económico. ${ }^{68}$

En el caso mexicano, las instituciones públicas le daban viabilidad a la creciente concentración de un sector privado que buscaba permanentemente limitar la esfera de actuación del sector público, muchas veces

${ }^{68}$ Gerschenkron, “Atraso”, 1973, y Amsden, Rise, 2001. 
en forma explícita. Adicionalmente, el capital extranjero tenía un peso creciente en la economía y en las fuentes de recursos de NAFINSA, sin que se establecieran criterios para definir sus ámbitos de actuación, mientras la industria no revertía su sesgo antiexportador.

En este contexto, la actuación de NAFINSA en la movilización de fondos vinculados a grandes proyectos de la industria básica y su actividad de promoción resultó crucial para la continuidad del proceso de industrialización en las décadas de los cuarenta y cincuenta. Sin embargo, esa labor de promoción industrial, ligada a una activa conducta empresarial llevada adelante por la institución, fue perdiendo importancia a medida que se fueron profundizando los preceptos estabilizadores en la política económica. Su labor emprendedora fue retomada en la década de los setenta, aunque en un contexto internacional complejo y con profundos desequilibrios que ya se habían acumulado en la economía mexicana.

\section{BIBLIOGRAFÍA}

Amsden, Alice, The Rise of the "Rest". Challenges to the West from Late-Industrializing Economies, Nueva York, Oxford University Press, 2001.

Ángel, Gustavo del, Paradoxes of Financial Development: the Construction of the Mexican Banking System. 1941-1982, Standford, Leland Stanford University, 2002.

y CARLOS MARICHAL, "Poder y crisis: historiografía reciente del crédito y la banca en México (siglos XIX y Xx)", Historia Mexicana, El Colegio de México, vol. 52, núm. 3 (207), enero-marzo de 2003, pp. 677-724.

Ares, MATHIU, "El Estado empresario: Nacional Financiera durante la industrialización por sustitución de importaciones (1934-1994)", Foro Internacional, El Colegio de México, vol. XLVII, núm. 2 (188), abril-junio de 2007, pp. 201-244.

Aubey, Robert, Nacional Financiera and the Mexican Industry: a Study of the Financial Relationship between the Government and the Private Sector of Mexico, Los Ángeles, University of California, 1966.

Ávila Camacho, Manuel, Primer informe de gobierno, México, Gobierno de la Unión, 1941.

BANCO DE MÉXICO, Informe anual, México, Banco de México, 1934-1986.

Basch, Atonin, El mercado de capitales en México, México, Centro de Estudios Monetarios Latinoamericanos/Banco Interamericano de Desarrollo, 1968.

Bennett, Douglas y Kenneth Sharpe, "The State as a Banker and Entrepreneur: The Last Resort Character of the Mexican State's Economic Intervention, 19171970" en Sylvia Hewlett y Richard Weinert (eds.), Brazil and Mexico: Patterns in Late Development, Filadelfia, Instutute for the Study of Human Issues, 1982. 
Blair, Calvin, "Nacional Financiera: Entrepreneurship in a Mixed Economy" en Raymond Vernon (dir.), Public Policy and Private Enterprise in Mexico, Cambridge, Harvard University Press, 1964, pp. 191-240.

Cámara de Diputados, Informes presidenciales. José López Portillo, México, Servicio de Investigación y Análisis, 2006.

Informes presidenciales. Miguel Alemán Valdez, México, Servicio de Investigación y Análisis, 2006.

Clavijo, Fernando (comp.), Reformas económicas en México, 1982-1999, México, Comisión Económica para América Latina y el Caribe/Estrategia y Análisis Económico, Consultores/Fondo de Cultura Económica, 2000 (Serie de Lecturas del Trimestre Económico, 93).

COMisión Económica PARA América latina y NaCiOnal Financiera, la política industrial en el desarrollo económico de México, México, Comisión Económica para América Latina y el Caribe, 1971.

Comisión Mixta del Gobierno de México y del Banco Internacional de ReCONSTRUCCIÓn y Fomento, El desarrollo económico de México y su capacidad para absorber capital del exterior, México, Nacional Financiera, 1953.

Falkowski, Daniel Carl, Nacional Financiera, S. A. de Mexico. A Study of a Development Bank, Nueva York, New York University, 1972.

FitzGerald, Edmund VAlpy KnOX, "El déficit presupuestal y el financiamiento de la inversión: una nota sobre la acumulación de capital en México" en Rolando Cordera Campos (coord.), Desarrollo y crisis de la economía mexicana, México, Fondo de Cultura Económica, 1981, pp. 214-239.

GARrido, CELSO, "Industrialización y grandes empresas en el desarrollo estabilizador”, Análisis Económico, Universidad Autónoma Metropolitana-unidad Azcapotzalco, vol. XVII, núm. 35, primer semestre de 2002, México, pp. 233-267.

Gerschenkron, Alexander, "El atraso económico en su perspectiva histórica" en Alexander Gerschenkron, Atraso económico e industrialización, Barcelona, Ariel, 1973.

Glade, William Patton, "Las empresas gubernamentales descentralizadas", Problemas Agrícolas e Industriales de México, vol. XI, núm. 1, enero-marzo de 1959, México.

Golsmith, Raymond, The Financial Development of Mexico, París, Organización para la Cooperación y el Desarrollo Económicos, 1966.

Gómez URRutia, NAPOlEón, "Estructura financiera, rentabilidad y crecimiento económico en México", Comercio Exterior, Banco Nacional de Comercio Exterior, vol. XXV, núm. 6, 1975, pp. 643-651.

GonzÁlez Méndez, Héctor E., Algunos aspectos de la concentración en el sistema financiero mexicano, México, Banco de México, marzo de 1981 (Serie Documentos de Investigación, 34).

Gracida Romo, Elsa M. y Esperanza Fujigaki Cruz, "La economía mexicana en el siglo XX: ¿̇grandes ilusiones, magros resultados?”, Ciclos en la Historia, la Economía y la Sociedad, Fundación de Investigaciones Históricas, Económicas y Sociales-Uni- 
versidad de Buenos Aires, año XV, vol. XV, núm. 30, segundo semestre de 2005, Buenos Aires.

Haber, Stephen, "Industrial Concentration and the Capital Markets: A Comparative Study of Brazil, Mexico and the United States, 1830-1930", The Journal of Economic History, Economic History Association, vol. 51, núm. 3, septiembre de 1991, pp. 559-580.

IzQuierdo, Rafael, Política hacendaria del desarrollo estabilizador, 1958-1970, México,

El Colegio de México/Fondo de Cultura Económica/Fideicomiso Historia de las Américas, 1995.

KALdor, NichOlas, "Las reformas al sistema fiscal en México" en LeOPOLdo Solís (comp.), La economía mexicana, vol. II: Política y desarrollo, México, Fondo de Cultura Económica, 1973, pp. 29-39 (Serie de Lecturas del Trimestre Económico, 4).

Marichal, CARlos, "Debates sobre los orígenes de la banca central en México", Coloquio México y España: Historia Económica Comparada, Centro de Investigaciones y Docencia Económicas, mayo de 2001.

"Auge y decadencia de las empresas estatales en México, 1930-1980: algunas notas sobre la relación histórica entre empresas estatales y endeudamiento externo", Antropología, Boletín Oficial del Instituto Nacional de Antropología e Historia, nueva época, 2003, México.

MaXfield, Sylvia, Governing Capital. International Finance and Mexican Politics, Ithaca y Londres, Cornell University Press, 1990.

Moore, O. ERnest, Evolución de las instituciones financieras en México, México, Centro de Estudios Monetarios Latinoamericanos, 1963.

Nacional Financiera, Informes anuales, México, Nacional Financiera, 1934-1986.

Nacional Financiera S. A. en el desarrollo económico de México, 1934-1964,

México, Nacional Financiera, 1964.

, 40 años en el desarrollo de México, México, Informe de la Dirección General al honorable Consejo de Administración de Nacional Financiera, 2 de julio 1974. , La economía mexicana en cifras, México, Nacional Financiera, 1974. La economía mexicana en cifras, México, Nacional Financiera, 1978. Medio siglo de banca de desarrollo. Testimonios de sus directores generales, México, Nacional Financiera, 1984.

Nacional Financiera 1934-1984, medio siglo de banca de desarrollo. Testimonios de sus directores generales, México, Nacional Financiera, 1985.

Legislación constitutiva y leyes orgánicas, 1934-1994, México, Nacional Financiera, 1994.

Ortiz Mena, Antonio, "Desarrollo estabilizador: Una década de estrategia económica en México" en Nafinsa (eds.), Testimonios del mercado de valores, México, t. 1, núm. 44, 1969.

, El desarrollo estabilizador: reflexiones sobre una época, México, El Colegio de México/Fondo de Cultura Económica/Fideicomiso Historia de las Américas, 1998. 
Ramírez, Miguel, Development Banking in Mexico. The Case of the Nacional Financiera, S. A., Nueva York, Praeger Publishers, 1986.

Reynolds, Clark, "Por qué el 'desarrollo estabilizador' de México fue en realidad desestabilizador”, El Trimestre Económico, Fondo de Cultura Económica, vol. XLIV, núm. 176, 1977, México, pp. 997-1023.

Solís Manjarrez, Leopoldo, La evolución de la economía mexicana, México, Colegio Nacional, 1999.

Villa, Rosa Olivia, Nacional Financiera: Banco de Fomento del Desarrollo Económico de México, México, Nacional Financiera S. A., 1976.

Villarreal, René, El desequilibrio externo en la industrialización de México (1929-1975). Un enfoque estructuralista, México, Fondo de Cultura Económica, 1976.

Zysman, JoHn, Governments, Markets and Growth: Financial Systems and the Politics of Industrial Change, Londres, Cornell University, 1983. 